\title{
Usefulness of Oscillations Added to Mechanical In-Exsufflation in Amyotrophic Lateral Sclerosis
}

\author{
Jesús Sancho, Enric Burés, Santos Ferrer, Elvira Bondía, and Emilio Servera
}

\begin{abstract}
BACKGROUND: Assisted coughing via mechanical in-exsufflation (MI-E) is a first-line treatment for secretion management in patients with amyotrophic lateral sclerosis (ALS) with unassisted $\mathrm{CPF}<4.25 \mathrm{~L} / \mathrm{s}$. Some devices enable oscillations to be added to MI-E (MI-E+O). We sought to determine whether adding oscillations to MI-E enables a reduction in the use of invasive secretion management procedures (ie, bronchoscopy or tracheostomy) in subjects with ALS. METHODS: We conducted a 12-month, prospective, randomized follow-up study of subjects with ALS for whom assisted coughing techniques were indicated. One group was treated with oscillations in addition to MI-E (MI-E+O), and the other group was treated with conventional MI-E. RESULTS: 29 subjects were included in the MI-E group and 27 subjects were included in the MI-E+O group. Five subjects (8.9\%) required invasive techniques for secretion management (3 in the MI-E group and 2 in the $\mathrm{MI}-\mathrm{E}+\mathrm{O}$ group, $P=.70$ ). Treatment with $\mathrm{MI}-\mathrm{E}+\mathrm{O}$ did not alter the risk of invasive procedures (odds ratio $0.69,95 \%$ CI $0.10-4.50, P=.70$ ). The mean number of respiratory infections was $0.58 \pm 0.16$ in the MI-E group and $0.025 \pm 0.08$ in the MI-E $+O$ group $(P=.10)$. Survival was $8.96 \pm 0.18$ months in the MI-E group and $7.70 \pm 0.70$ months in the MI-E $+O$ group $(P=.10)$. CONCLUSION: Adding oscillations to MI-E did not enable a reduction in the need to perform invasive procedures for secretion management in subjects with ALS. Key words: amyotrophic lateral sclerosis; cough-assist; mechanical insufflation-exsufflation; survival; chest infection; bronchoscopy. [Respir Care 2020;65(5):596-602. ㅇ 2020 Daedalus Enterprises]
\end{abstract}

\section{Introduction}

The effective removal of respiratory secretions is a key issue for the successful management of respiratory problems in patients with amyotrophic lateral sclerosis (ALS). ${ }^{1}$ Motor neuron degeneration leads to weakness of the in-

All authors are affiliated with the Respiratory Care Unit, Respiratory Medicine Department, Hospital Clinico Universitario, Valencia, Spain. Mr Sancho, Mr Burés, Mr Ferrer, and Mr Servera are affiliated with the Research Group for Respiratory Problems in Neuromuscular Diseases, INCLIVA Health Research Institute, Valencia, Spain. Mr Servera is also affiliated with the University of Valencia, Spain.

Mr Burés discloses relationships with Philips-Respironics and the Institute of Health Research INCLIVA. The other authors have disclosed no conflicts of interest.

Correspondence: Jesus Sancho PhD MD, Respiratory Care Unit, Respiratory Medicine Department, Hospital Clinico Universitario, Avd Blasco Ibañez 17, 46010 Valencia, Spain. E-mail: jesus.sancho@uv.es.

DOI: $10.4187 /$ respcare. 07202 spiratory, expiratory, and bulbar muscles, causing a decrease in cough effectiveness. During an acute chest infection, ineffective coughing may lead to a life-threatening encumbrance of respiratory secretions in patients with ALS. ${ }^{2}$ Respiratory failure may follow due to ventilationperfusion mismatch and the subsequent overload of inspiratory muscles, requiring the performance of endotracheal intubation and mechanical ventilation. ${ }^{2}$

The assisted coughing technique of mechanical insufflation-exsufflation (MI-E) has proven its effectiveness in noninvasive respiratory secretion removal in most patients with ALS who have an ineffective cough. ${ }^{3}$ Consequently, MI-E is recommended as a first-line treatment for mucus removal in patients with ALS, but the degree of its effectiveness is determined by the severity of bulbar dysfunction. ${ }^{4}$ Despite the utility of MI-E in these patients, invasive procedures such as bronchoscopy or tracheostomy are sometimes needed to remove thick secretions and mucus plugs that adhere to the tracheobronchial walls. ${ }^{3}$

Some airway clearance techniques that seek to move mucus from the peripheral airways to the central air- 


\section{Oscillation With MI-E IN ALS}

ways apply high-frequency oscillations, either from within the lungs or from around the chest. ${ }^{5}$ Several mechanisms have been proposed as explanations of the

\section{See the Related Editorial on Page 725}

physiological effects of oscillations. With oscillations, a cephalad movement of mucus is produced as a result of air flow bias generated by the air-liquid shear forces. ${ }^{6}$ Moreover, sputum viscosity is reduced, presumably by altering the crosslink density of mucus glycoproteins. ${ }^{6,7}$ It has also been proposed that oscillations produce an enhancement in ciliary beating. ${ }^{7}$ Techniques using oscillations are advocated for their ability to mobilize secretions rather than to increase CPF. ${ }^{8}$ In an attempt to combine the effects of MI-E and peripheral airway clearance techniques, some devices now offer the feature of adding oscillations to MI-E (MI-E+O). These oscillations are generated by air pulses resulting from constant changes in the pressure applied (during insufflation, exsufflation, or in both cycles) with a set frequency.

Adding oscillations to MI-E in medically stable patients with ALS has been reported to have no effect on CPF. ${ }^{9}$ However, no studies have been published to assess the utility of adding oscillations to MI-E for secretion removal. Thus, the aim of this study was to determine whether adding oscillations to MI-E reduces the need for invasive procedures for mucus removal in ALS in an effort to improve the noninvasive management of respiratory problems in ALS patients.

\section{Methods}

This was a prospective randomized study lasting 2 years and included clinically stable patients with ALS diagnosed according to the revised El Escorial criteria, ${ }^{10}$ with an unassisted cough in a medically stable condition that was at risk of becoming ineffective during an acute chest infection $(\mathrm{CPF}<4.25 \mathrm{~L} / \mathrm{s}),{ }^{3}$ and possessing effective mechanically assisted CPF (ie, $>2.67 \mathrm{~L} / \mathrm{s}$ ). ${ }^{11}$ Subjects were recruited from among patients with ALS who entered our respiratory care unit between January 2015 and December 2016. Exclusion criteria were refusal to participate in the study, the presence of lung disease, contraindications for the use of MI-E, or the presence of severe frontotemporal dementia associated with ALS that could interfere with procedures. Informed consent was obtained, and the protocol was approved by the hospital's ethics committee. The study protocol was registered at the INCLIVA Health Research Institute in Valencia, Spain (2014/076).

After inclusion in the study, subjects underwent a clinical assessment and a functional respiratory evalu-

\section{QUICK LOOK}

\section{Current knowledge}

Assisted coughing via mechanical insufflation-exsufflation (MI-E) is a first-line treatment for secretion management in patients with amyotrophic lateral sclerosis. To increase its effectiveness, some devices enable oscillations to be added to MI-E. However, no studies have been published to assess the utility of oscillations added to MI-E.

\section{What this paper contributes to our knowledge}

The noninvasive use of oscillations added to MI-E to manage respiratory secretions in subjects with amyotrophic lateral sclerosis did not reduce the need to perform invasive procedures for mucus removal. Moreover, the addition of oscillations to MI-E did not decrease the risk of respiratory tract infections, nor did it improve 1-year survival.

ation. The clinical assessment was performed using the Revised Amyotrophic Lateral Sclerosis Scale (ALSFRS$\mathrm{R}),{ }^{12}$ and bulbar dysfunction was assessed in accordance with the Norris scale bulbar subscore. ${ }^{13}$ The respiratory function assessment included spirometry (MS 2000, C. Schatzman, Madrid, Spain) performed in accordance with European Respiratory Society guidelines and suggested reference values. ${ }^{14}$ Maximum inspiratory pressure $\left(\mathrm{P}_{\text {Imax }}\right)$ and maximum expiratory pressure $\left(\mathrm{P}_{\text {Emax }}\right)$ at the mouth were measured (Electrometer 78.905, Hewlett-Packard, Andover, MA) according to the Black and Hyatt technique. ${ }^{15}$ Sniff nasal inspiratory pressure was measured in an occluded nostril during a maximum sniff through the contralateral nostril (Micro RPM, MicroMedical, Rochester, Kent, United Kingdom). ${ }^{16}$ Maximum insufflation capacity, CPF, and manually and mechanically assisted CPF were measured as described in previous studies. ${ }^{3}$

The subjects included in this protocol were randomized into 2 groups: one group was assigned conventional treatment using MI-E (E70, Philips-Respironics, Murrysville, PA), and the other group was assigned treatment using MI-E with oscillations (MI-E $+\mathrm{O}$ ) added in both the insufflation and exsufflation cycles. Both groups were trained in the use of the device, both for regular daily use and during acute respiratory infections; every subject enrolled in the study was observed for a period of 1 year.

MI-E was provided using an oronasal mask. It was set according to patient tolerance and to achieve an effective mechanically assisted $\mathrm{CPF}$ (ie, $>2.65 \mathrm{~L} / \mathrm{s}$ ). ${ }^{8} \mathrm{Os}-$ cillations were applied with a frequency of $15 \mathrm{~Hz}$ and an 


\section{Oscillation With MI-E IN ALS}

amplitude of $10 \mathrm{~cm} \mathrm{H}_{2} \mathrm{O}$. When the subjects were in a medically stable condition, 2 sessions of $6-8$ cycles were applied each day and additionally when necessary due to secretion encumbrance. During acute respiratory infections, MI-E treatment was provided at least twice every $8 \mathrm{~h}$ and whenever the subject experienced an increase in dyspnea, a sensation of retained secretions, or, in the case of the use of home noninvasive ventilation, the ventilator peak inspiratory pressure increased or $\mathrm{S}_{\mathrm{pO}_{2}}$ decreased. ${ }^{2,17}$ In accordance with European Respiratory Society Guidelines, ${ }^{18}$ subjects were said to be suffering an acute lower respiratory tract infection in the presence of a cough with one or more of the following criteria: sputum production, dyspnea, wheezing, or chest discomfort. Criteria for hospitalizations during an acute respiratory infection at the respiratory care unit were respiratory failure, the need for ventilatory support (invasive or noninvasive), the need for intensive MI-E (ie, $>4$ sessions per hour), the need for intravenous medication, the presence of persistent dyspnea despite appropriate management at home, the inability to remove mucus with mechanically assisted coughing techniques at home, or an episode of $\mathrm{S}_{\mathrm{pO}_{2}}<90 \%$ during a respiratory tract infection that could not be relieved at home with noninvasive ventilation and MI-E. ${ }^{2,18}$

During the study period, a scheduled clinical and functional assessment was undertaken every 3 months. In addition, monthly telephone calls were made to collate data on both groups regarding their clinical respiratory situations.

\section{Outcomes}

The primary outcome was the need for a bronchoscopy or a tracheostomy for mucus removal due to ineffective MI-E within the study year after randomization. Secondary outcomes included the number of respiratory tract infections, the number of hospitalizations due to respiratory tract infections and the outcomes of these hospitalizations, and the rate of the decline of respiratory parameters during the period of the study.

A subanalysis was made for those subjects who required hospital admission due to an acute respiratory tract infection. During these episodes, as well as during medical treatment and noninvasive ventilation when necessary, respiratory secretions were managed with mechanically assisted coughing in the same way as they had been at home (ie, with or without oscillations). Data were collected with regard to the outcome of these episodes (ie, discharge, death, tracheostomy), days spent in hospital, and the need for an bronchoscopy or a tracheostomy to remove secretions due to ineffective MI-E.

\section{Statistical Analysis}

Assuming a risk of 5\% and a power of $80 \%$ to detect differences, basing our results on results concerning ALS subjects reported in previous studies, ${ }^{2,3,5}$ and considering success to be the avoidance of invasive procedures for mucus removal, a sample size of 60 was needed to detect differences with an estimated patient dropout rate of $10 \%$.

Binary and categorical variables were summarized using frequency counts and percentages. Continuous normally distributed variables were expressed as mean $\pm \mathrm{SD}$; data that was not normally distributed were expressed as medians. All primary and secondary analyses were made according to the intention-to-treat principle. Data comparisons were performed using the Student $t$ test and the Mann-Whitney test for normally and non-normally distributed data, respectively. Dichotomic variables were compared with the chi-squared test. Logistic regression analysis was performed with and without adjusting for variables related to ineffective MI-E (ALS onset, mechanically assisted CPF, ALSFRS-R, and Norris scale bulbar subscore). ${ }^{2,8}$ Survival was considered as the time from study inclusion to tracheostomy (or death if tracheostomy was refused) and was assessed with Kaplan-Meier charts, applying a log-rank test for between-group comparisons. Adjusted and unadjusted risk of tracheostomy or death due to failure of MI-E was analyzed using a Cox proportional hazards regression model. Statistical significance was taken as $P<.05$.

\section{Results}

During the study period, 61 patients with ALS presented CPF values $<4.25 \mathrm{~L} / \mathrm{s}$, with mechanically assisted $\mathrm{CPF}$ $>2.67 \mathrm{~L} / \mathrm{s}$, but 5 did not meet the inclusion criteria (4 due to severe frontotemporal dementia and 1 due to lung pathology). Thus, 56 subjects with ALS were enrolled in the study and were randomized; 29 were assigned to the MI-E group and 27 were assigned to the MI-E $+\mathrm{O}$ group (Fig. 1). No statistical differences were found between the 2 groups in demographic, respiratory function, or functional assessment values upon inclusion in the study (Table 1). At the time of randomization, $65.1 \%$ of subjects in the MI-E group were using noninvasive ventilation at home; this figure was $70.4 \%$ in the MI-E $+\mathrm{O}$ group $(P=.61)$. No differences were found in time using noninvasive ventilation at home over the course of the day $(10.3 \pm 5.3$ vs $12.8 \pm 7.1 \mathrm{~h}, P=.21$ ). Of the subjects in the MI-E group, $41.4 \%$ had a gastrostomy for enteral nutrition, whereas $33.3 \%$ of subjects in the MI-E+O group had a gastrostomy $(P=.53)$.

No subject reported complications related to the mechanically assisted cough treatment during the study pe- 


\section{Oscillation With MI-E IN ALS}

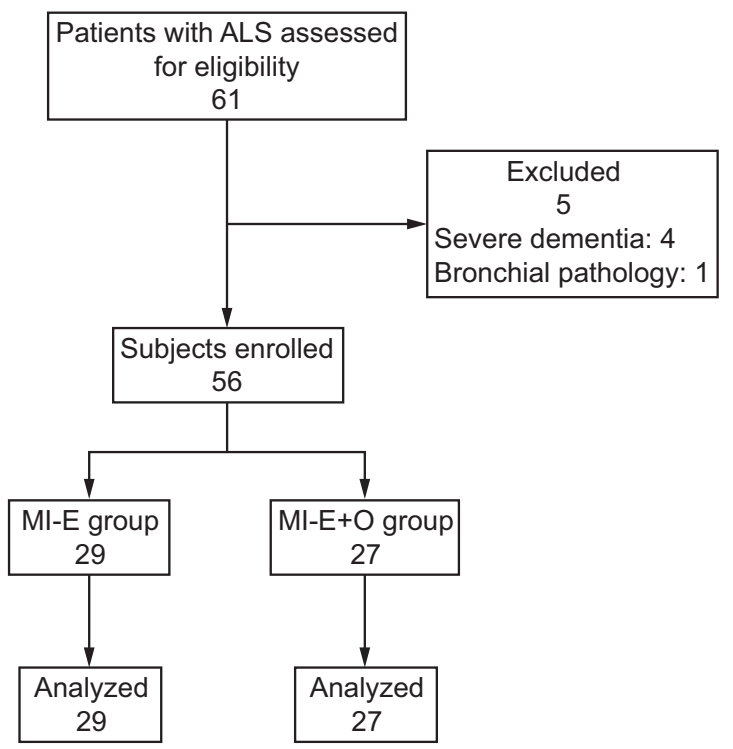

Fig. 1. Flow chart. ALS = amyotrophic lateral sclerosis; $M I-E=$ mechanical insufflation-exsufflation; $\mathrm{O}=$ oscillations.

riod and none withdrew from the study. The mean set parameters used for MI-E were $35.7 \pm 3.6 \mathrm{~cm} \mathrm{H}_{2} \mathrm{O}$ for the insufflation pressure, $-40.4 \pm 1.1 \mathrm{~cm} \mathrm{H}_{2} \mathrm{O}$ for the exsufflation pressure, $1.7 \pm 0.5 \mathrm{~s}$ for the insufflation time, and $2.9 \pm 0.2 \mathrm{~s}$ for the exsufflation time.

The mean number of respiratory infections in the whole population during the 12-month follow-up period was
$0.42 \pm 0.73(0.58 \pm 0.16$ in the MI-E group and $0.25 \pm 0.08$ in the MI-E+O group, $P=.10)$. Eight subjects $(27.6 \%)$ suffered a respiratory infection episode in the MI-E group, and 10 subjects $(37.0 \%)$ in the $\mathrm{MI}-\mathrm{E}+\mathrm{O}$ group experienced a respiratory infection episode $(P=.34)$. For a respiratory tract infection within 12 months, there was an adjusted odds ratio of 0.44 (95\% CI $0.09-2.02, P=.30$ ) and an unadjusted odds ratio of 0.57 (95\% CI $0.18-1.79, P=.34$ ).

Within the 12-month follow-up period, 5 subjects (8.9\%) presented with a failure of MI-E requiring invasive procedures to remove secretions ( 3 subjects in the MI-E group and 2 in the MI-E $+\mathrm{O}$ group, $P=.70$ ). Bronchoscopy was performed in each case, and a tracheostomy was indicated for 4 subjects ( 2 subjects refused the tracheostomy). No subjects suffered complications related to the bronchoscopy or the tracheostomy. With regard to the need for invasive procedures to remove respiratory secretions, the adjusted odds ratio was 0.69 (95\% $\mathrm{CI} 0.10-4.50, P=.70$ ), and the unadjusted odds ratio was 0.25 (95\% CI 0.02 $2.95, P=.27$ ).

At the end of the study, a tracheostomy had been performed in 5 subjects and 25 subjects died without a tracheostomy. The causes of tracheostomy and death were ineffective noninvasive ventilation due to severe bulbar dysfunction $(n=10)$, sudden death $(n=6)$, failure of respiratory secretion management $(n=4)$, ineffective noninvasive ventilation and failure of secre-

Table 1. Demographic and Pulmonary Function in the Total Population and the MI-E and MI-E+O Groups

\begin{tabular}{|c|c|c|c|c|}
\hline & Total Population & MI-E Group & MI-E+O Group & $P$ \\
\hline Age, y & $69.3 \pm 10.2$ & $68.6 \pm 9.3$ & $70.1 \pm 11.2$ & .57 \\
\hline Gender (male/female), $n$ & $27 / 29$ & $11 / 18$ & $16 / 11$ & .11 \\
\hline Onset (spinal/bulbar), $n$ & $34 / 22$ & $19 / 10$ & $15 / 12$ & .45 \\
\hline Time from ALS onset, months & $47.9 \pm 44.9$ & $51.13 \pm 48.6$ & $44.34 \pm 41.25$ & .58 \\
\hline Body mass index, $\mathrm{kg} / \mathrm{m}^{2}$ & $26.20 \pm 4.67$ & $25.92 \pm 4.17$ & $27.53 \pm 4.87$ & .067 \\
\hline ALSFRS-R & $23.83 \pm 7.77$ & $23.24 \pm 7.60$ & $24.47 \pm 8.08$ & .59 \\
\hline Norris scale bulbar subscore & $22.22 \pm 12.02$ & $22.38 \pm 12.74$ & $22.04 \pm 11.44$ & .92 \\
\hline FVC, L & $1.16 \pm 0.61$ & $1.08 \pm 0.55$ & $1.24 \pm 0.67$ & .33 \\
\hline$\%$ of predicted FVC & $40.89 \pm 19.37$ & $39.72 \pm 17.65$ & $42.14 \pm 21.34$ & .64 \\
\hline FVC supine, $\mathrm{L}$ & $0.97 \pm 0.52$ & $0.96 \pm 0.59$ & $0.99 \pm 0.43$ & .85 \\
\hline Maximum insufflation capacity, L & $1.43 \pm 0.67$ & $1.42 \pm 0.68$ & $1.44 \pm 0.69$ & .94 \\
\hline $\mathrm{CPF}, \mathrm{L} / \mathrm{s}$ & $2.60 \pm 1.41$ & $2.63 \pm 1.42$ & $2.57 \pm 1.42$ & .87 \\
\hline Manually-assisted CPF, L/s & $2.79 \pm 1.34$ & $2.82 \pm 1.36$ & $2.75 \pm 1.34$ & .86 \\
\hline Mechanically-assisted CPF, L/s & $2.98 \pm 0.94$ & $2.95 \pm 0.95$ & $3.01 \pm 0.96$ & .81 \\
\hline $\mathrm{P}_{\text {Imax }}, \mathrm{cm} \mathrm{H}_{2} \mathrm{O}$ & $-24.33 \pm 14.03$ & $-22.75 \pm 12.93$ & $-26.12 \pm 15.23$ & .39 \\
\hline $\mathrm{P}_{\text {Emax }}, \mathrm{cm} \mathrm{H}_{2} \mathrm{O}$ & $38.53 \pm 29.20$ & $34.24 \pm 21.95$ & $43.52 \pm 35.67$ & .25 \\
\hline Sniff inspiratory pressure, $\mathrm{cm} \mathrm{H}_{2} \mathrm{O}$ & $-24.13 \pm 19.75$ & $-20.71 \pm 12.83$ & $-27.96 \pm 25.13$ & .20 \\
\hline $\begin{array}{l}\text { Total population: } N=56 ; \text { MI-E group: } n=29 \\
\text { ALSFRS-R = Revised Amyotrophic Lateral Sc } \\
\text { MI-E }=\text { mechanical insufflation-exsufflation } \\
\text { MI-E }+\mathrm{O}=\text { mechanical insufflation-exsufflation } \\
\text { CPF }=\text { cough peak flow } \\
\mathrm{P}_{\text {Emax }}=\text { maximum expiratory pressure } \\
\mathrm{P}_{\text {Imax }}=\text { maximum inspiratory pressure }\end{array}$ & $\begin{array}{l}n=27 . \\
\text { Rating Score }\end{array}$ & & & \\
\hline
\end{tabular}




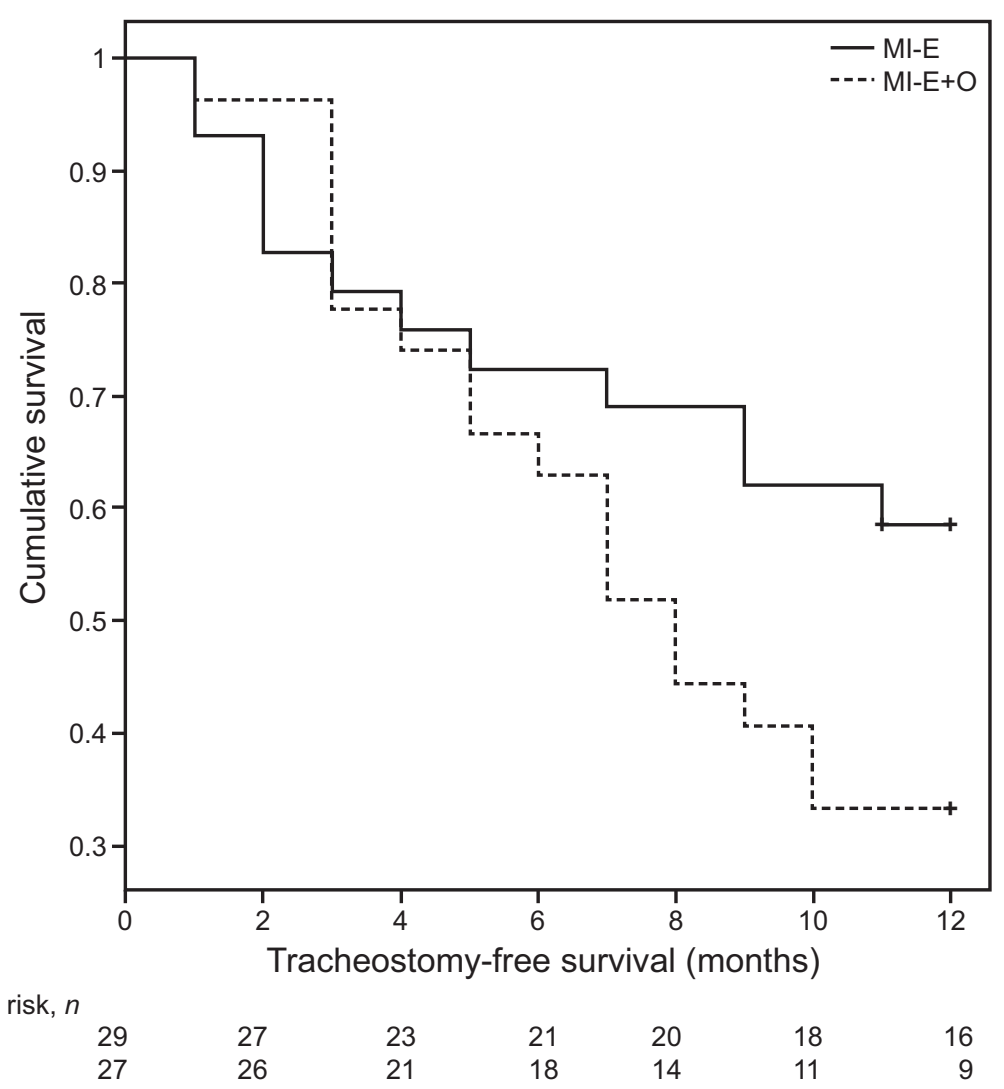

Fig. 2. Cumulative survival and 1-year tracheostomy-free survival. MI-E = mechanical insufflation-exsufflation; $\mathrm{O}=$ oscillations.

tion management $(n=4)$, refusal to continue with respiratory muscle aids $(n=2)$, and other causes $(n=4)$. Survival was $8.96 \pm 0.18$ months in the MI-E group and $7.70 \pm 0.70$ months in the MI-E+O group $(P=.10)$ (Fig. 2). The unadjusted hazard ratio for failure (tracheostomy or death) within the 12-month study period was 0.65 (95\% CI $0.09-4.64, P=.67)$, and the adjusted hazard ratio was 1.44 (95\% CI $0.12-17.08, P=.77)$. No statistical differences were found between the groups in the rate of deterioration in functional respiratory parameters over the year studied (Table 2).

\section{Episodes of Severe Respiratory Infection}

In the MI-E group, 8 subjects required hospitalization due to a severe respiratory infection, with a total of 9 hospital admissions; 10 subjects required 11 hospital admissions in the MI-E $+\mathrm{O}$ group $(P=.44)$. For the MI-E group and the MI-E $+\mathrm{O}$ group, mean hospitalizations during the study were $0.31 \pm 0.54$ and $0.40 \pm 0.57$ $(P=.45)$, respectively, and the mean hospital stays were $3.67 \pm 9.45 \mathrm{~d}$ and $5.25 \pm 10.93 \mathrm{~d}(P=.57)$, respectively. Five subjects required invasive procedures for secretion management (ie, bronchoscopy) during episodes of severe respiratory infection as reported above; of these, 2 subjects underwent tracheostomy and 2 sub- jects died after refusing tracheostomy. No statistical differences was found between the 2 groups.

Table 2. Rate of Deterioration in Functional Respiratory Parameters Over 1 Year

\begin{tabular}{|c|c|c|c|}
\hline & MI-E Group & $\begin{array}{l}\text { MI-E }+\mathrm{O} \\
\text { Group }\end{array}$ & $P$ \\
\hline $\mathrm{FVC}, \mathrm{mL}$ & $11.22 \pm 47.73$ & $38.08 \pm 66.28$ & .22 \\
\hline FVC supine, $\mathrm{mL}$ & $25.46 \pm 47.73$ & $21.88 \pm 51.80$ & .88 \\
\hline $\begin{array}{l}\text { Maximum insufflation } \\
\text { capacity, } \mathrm{mL}\end{array}$ & $20.57 \pm 57.12$ & $9 \pm 110.72$ & .38 \\
\hline $\mathrm{CPF}, \mathrm{L} / \mathrm{s}$ & $0.06 \pm 0.90$ & $0.08 \pm 0.16$ & .74 \\
\hline $\begin{array}{l}\text { Manually-assisted CPF, } \\
\text { L/s }\end{array}$ & $0.04 \pm 0.09$ & $0.10 \pm 0.24$ & .43 \\
\hline $\begin{array}{l}\text { Mechanically-assisted } \\
\text { CPF, L/s }\end{array}$ & $0.04 \pm 0.09$ & $0.02 \pm 0.09$ & .41 \\
\hline $\mathrm{P}_{\text {Imax }}, \mathrm{cm} \mathrm{H}_{2} \mathrm{O}$ & $0.33 \pm 1.11$ & $0.96 \pm 1.39$ & .21 \\
\hline $\mathrm{P}_{\text {Emax }}, \mathrm{cm} \mathrm{H}_{2} \mathrm{O}$ & $0.45 \pm 1.98$ & $1.44 \pm 3.25$ & .35 \\
\hline $\begin{array}{l}\text { Sniff inspiratory pressure, } \\
\qquad \mathrm{cm} \mathrm{H}_{2} \mathrm{O}\end{array}$ & $0.47 \pm 1.24$ & $2.01 \pm 4.98$ & .27 \\
\hline $\begin{array}{l}\text { MI-E group: } n=29 ; \text { MI-E }+\mathrm{O} \text { grou } \\
\text { MI-E = mechanical insufflation-exs } \\
\text { MI-E }+\mathrm{O}=\text { mechanical insufflation- } \\
C P F=\text { cough peak flow } \\
\mathrm{P}_{\text {Emax }}=\text { maximum expiratory press } \\
\mathrm{P}_{\text {Imax }}=\text { maximum inspiratory press }\end{array}$ & $\begin{array}{l}=27 \\
\text { ation } \\
\text { ufflation with oscilla }\end{array}$ & & \\
\hline
\end{tabular}




\section{Oscillation With MI-E IN ALS}

\section{Discussion}

Our results indicate that the noninvasive use of oscillations with MI-E for respiratory secretion management in subjects with ALS does not reduce the need to perform invasive procedures for mucus removal; moreover, the addition of oscillations to MI-E does not decrease the risk of respiratory tract infections nor improve 1-year survival compared to MI-E alone.

This is the first published study designed to assess the effects of adding high-frequency oscillations to MI-E in subjects with ALS, both for long-term use at home to prevent respiratory complications related to secretions and during a decline in respiratory status to avoid noninvasive secretion management failure. A previous study using conventional MI-E in subjects with ALS reported that $32 \%$ of subjects suffered an acute respiratory infection despite longterm use of MI-E, ${ }^{19}$ with $16-21 \%$ of subjects needing hospitalization. ${ }^{3,19}$ Moreover, around $7 \%$ of patients with ALS treated with MI-E who are admitted to a hospital require a bronchoscopy for mucus removal.2,20 Our results are similar, regardless of the type of MI-E used: $32 \%$ of our subjects suffered a respiratory tract infection over the year, $32.1 \%$ required hospitalization due to a severe chest infection, and $8.9 \%$ of our subjects required a bronchoscopy for mucus removal due to MI-E failure. Previous studies using small sample sizes to assess the effect of high-frequency oscillation techniques in comparison with no treatment or conventional management of subjects with ALS have reported no increase in survival, no changes in the rate of decline in FVC, and no changes in hospitalizations or tracheostomies. ${ }^{21,22}$ These negative results can be explained by the fact that, after the use of oscillations, proximal airway clearance techniques are still needed to clear secretions from the central airways. ${ }^{4}$

Our study was designed to assess the effectiveness of adding oscillations to MI-E in 2 different situations in subjects with ALS: during regular daily use over the course of a year, and during acute deterioration in respiratory status in which the amount, purulence, and viscosity of respiratory secretions increase and respiratory muscle weakness may become life-threatening. The results of our study indicate that the long-term addition of oscillations to MI-E in clinically stable subjects with ALS does not reduce the risk of respiratory tract infections, nor does it produce any benefit in the rate of deterioration in functional respiratory parameters. Moreover, our findings show that, during an acute respiratory infection that is managed noninvasively, adding oscillations to MI-E for the purpose of improving respiratory secretion management does not reduce the risk of invasive procedures (eg, bronchoscopy or tracheostomy) being required for removal of respiratory secretions. In addition, no differences were found in 1-year survival between the MI-E and MI-E+O groups. Simi- larly, the adjusted risk for long-term noninvasive management failure, taking into account only noninvasive management failure due to ineffective respiratory secretion management, was not significantly different.

The severity of bulbar dysfunction is the factor that determines the effectiveness of MI-E for secretion management in patients with ALS. ${ }^{23}$ Insufflation and exsufflation induce a variety of upper airway responses depending on the degree of both upper and lower motor neuron dysfunction, predominantly at the bulbar level. The upper airway response conditions the mechanically-assisted CPF that are generated, and therefore is the gauge of the technique's effectiveness. ${ }^{23}$ Thus, the results of our study in subjects with ALS may be caused by the interaction of bulbar dysfunction with oscillations. Henke and Sullivan ${ }^{24}$ found, in normal subjects during sleep, that the application of oscillations produced activity in the upper airway muscles. Recently Andersen et al ${ }^{25}$ reported that oscillations promoted a variety of laryngeal movements in subjects with ALS, namely severe adduction and abduction during both insufflation and exsufflation.

The main limitations of this study are related to the use of a single value for the frequency and amplitude of the oscillations and the fact that oscillations were applied in both exsufflation and insufflation. The values we selected for frequency and amplitude are in the range of those used or generated with peripheral airway clearance techniques applying oscillations. ${ }^{26,27}$ Moreover, Andersen et al ${ }^{25}$ reported that using an amplitude of $10 \mathrm{~Hz}$ (the same value that we used) achieved a more stable laryngeal opening in some cases compared to conventional MI-E.

\section{Conclusions}

The addition of oscillations to noninvasive MI-E therapy in subjects with ALS did not reduce the need for invasive procedures to remove respiratory secretions, nor did it reduce the risk of acute respiratory infections. Moreover, the addition of oscillations to MI-E modified neither the rate of deterioration of respiratory parameters nor 1-year survival.

\section{REFERENCES}

1. Bach JR. Amyotrophic lateral sclerosis: prolongation of life by noninvasive respiratory aids. Chest 2002;122(1):92-98.

2. Servera E, Sancho J, Bañuls P, Marin J. Bulbar impairment score predicts noninvasive volume-cycled ventilation failure during an acute lower respiratory tract infection in ALS. J Neurol Sci 2015;358 $(1-2): 87-91$

3. Sancho J, Servera E, Díaz J, Marín J. Predictors of ineffective cough during a chest infection in patients with stable amyotrophic lateral sclerosis. Am J Respir Crit Care Med 2007;175(12):1266-1271.

4. Toussaint M, Chatwin M, Gonzales J, Berlowitz DJ; ENMC Respiratory Therapy Consortium. 228th ENMC International Workshop: Airway Clearance Techniques in Neuromuscular Disorders. Naarden, 


\section{Oscillation With MI-E IN ALS}

The Netherlands, 3-5 Mar, 2017. Neuromuscul Disord 2018;28(3): 289-298.

5. Chatburn RL. High-frequency assisted airway clearance. Respir Care 2007;52(9):1224-1235.

6. Sturgess JM, Palfrey AJ, Reid L. The viscosity of bronchial secretion. Clin Sci 1970;38(1):145-156.

7. King M, Phillips DM, Gross D, Vartian V, Chang HK, Zidulka A. Enhanced tracheal mucus clearance with high frequency chest wall compression. Am Rev Respir Dis 1983;128(3):511-515.

8. Bott J, Blumenthal S, Buxton M, Ellum S, Falconer C, Garrod R, et al. Guidelines for physiotherapy management of the adult, medical, spontaneously breathing patient. Thorax 2009;64(Suppl 1):i1-i52.

9. Sancho J, Bures E, de La Asunción S, Servera E. Effect of highfrequency oscillations on CPF generated by mechanical in-exsufflation in medically stable subjects with amyotrophic lateral sclerosis. Respir Care 2016;61(8):1051-1058.

10. Brooks BR, Miller RG, Swash M, Munsat TL, World Federation of Neurology Research Group on Motor Neuron Diseases. El Escorial revisited: revised criteria for the diagnosis of amyotrophic lateral sclerosis. Amyotroph Lateral Scler Other Motor Neuron Disord 2000; 1(5):293-299.

11. Sancho J, Servera E, Bañuls P, Marín J. Effectiveness of assisted and unassisted cough capacity in amyotrophic lateral sclerosis. Amyotroph Lateral Scler Frontotemporal Degener 2017;18(7-8):498-504.

12. Cedarbaum JM, Stambler N, Nalta E, Fuller C, Hilt D, Thurmond B, Nakanishi A. The ALSFRS-R: a revised ALS functional rating scale that incorporates assessments of respiratory function. BDNF ALS Study Group (Phase III). J Neurol Sci 1999;169(1-2):13-21.

13. Lacomblez LA, Bouche P, Bensimon G, Meininger V. A doubleblind, placebo-controlled trial of high doses of gangliosides in amyotrophic lateral sclerosis. Neurology 1989;39(12):1635-1637.

14. Quanjer PH, Tammeling GJ, Cotes JE, Pedersen OF, Peslin R, Yernault JC. Lung volumes and forced ventilatory flows. Report Working Party Standardization of Lung Function Tests, European Community for Steel and Coal. Official Statement of the European Respiratory Society. Eur Respir J Suppl 1993;16:5-40.

15. Black LF, Hyatt RE. Maximal respiratory pressures: normal values and relationship to age and sex. Am Rev Respir Dis 1969;99(5):696702 .

16. Lofaso F, Nicot F, Lejaille M, Falaize L, Louis A, Clement A, et al. Sniff nasal inspiratory pressure: what is the optimal number of sniffs? Eur Respir J 2006;27(5):980-982.
17. Bach JR, Bianchi C, Aufiero E. Oximetry and indications for tracheotomy for amyotrophic lateral sclerosis. Chest 2004;126(5):15021507.

18. Woodhead M, Blasi F, Ewig S, Garau J, Hucho G, Ieven M, et al. Guidelines for the management of adult lower respiratory tract infections-full version. Clin Microbiol Infect 2011;17(Suppl 6):E1E59.

19. Rafiq MK, Bradburn M, Proctor AR, Billings CG, Bianchi S, McDermott CJ, Shaw PJ. A preliminary randomized trial of the mechanical insufflator-exsufflator versus breath-stacking technique in patients with amyotrophic lateral sclerosis. Amyotroph Lateral Scler Frontotemporal Degener 2015;16(7-8):448-455.

20. Pisa FE, Logroscino G, Giacomelli Battiston P, Barbone F. Hospitalizations due to respiratory failure in patients with amyotrophic lateral sclerosis and their impact on survival: a population-based cohort study. BMC Pulm Med 2016;16(1):136.

21. Chaisson KM, Walsh S, Simmonds Z, Vender RL. A clinical pilot study: High frequency chest wall oscillation airway clearance in patients with amyotrophic lateral sclerosis. Amyotroph Lateral Scler 2006;7(2):107-111.

22. Lange DJ, Lechtzin N, Davey C, David W, Heiman-Patterson T, Gelinas D, et al. High-frequency chest wall oscillation in ALS: an exploratory randomized, controlled trial. Neurology 2006;67(6):991997.

23. Andersen T, Sandnes A, Brekka AK, Hilland M, Clemm H, Fondenes $\mathrm{O}$, et al. Laryngeal response patterns influence the efficacy of mechanical assisted cough in amyotrophic lateral sclerosis. Thorax 2017;72(3):221-229.

24. Henke KG, Sullivan CE. Effects of high-frequency oscillating pressures on upper airway muscles in humans. J Appl Physiol 1993; 75(2):856-862.

25. Andersen TM, Sandnes A, Fondenes O, Nilsen RM, Tysnes OB, Heimdal $\mathrm{JH}$, et al. Laryngeal responses to mechanically assisted cough in progressing amyotrophic lateral sclerosis. Respir Care 2018; 63(5):538-549.

26. Toussaint M, Guillet MC, Paternotte S, Soudon P, Haan J. Intrapulmonary effects of setting parameters in portable intrapulmonary percussive ventilation devices. Respir Care 2012;57(5):735-742.

27. Chatwin M, Toussaint M, Gonçalves MR, Sheers N, Mellies U, Gonzalez-Bermejo J, et al. Airway clearance techniques in neuromuscular disorders: a state of the art review. Respir Med 2018;136:98-110.

This article is approved for Continuing Respiratory Care Education credit. For information and to obtain your CRCE

(free to AARC members) visit

www.rcjournal.com

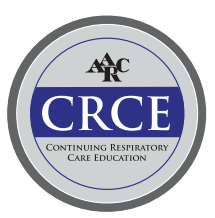

